\title{
Undergraduates' self-reported clinical experience, confidence and perspectives of hospital and outreach paediatric dentistry: a three-year multi-centre evaluation
}

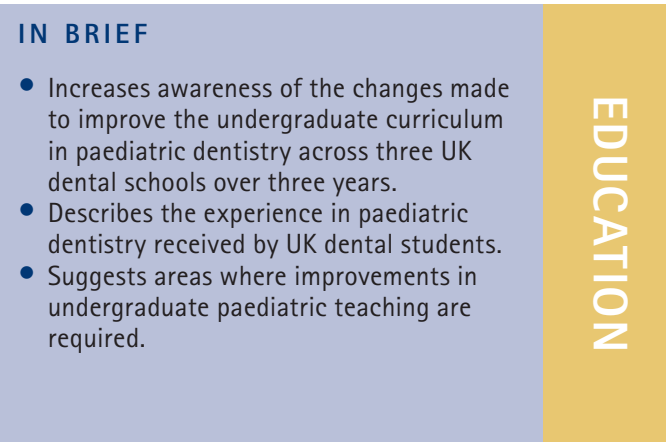

\author{
S. Walley, ${ }^{* 1}$ J. R. Bailey, ${ }_{1}^{2}$ S. Albadri, ${ }^{3}$ I. C. Mackie, ${ }_{1}^{4}$ F. Gilchrist ${ }^{5}$ \\ and H. D. Rodd 6
}

\section{VERIFIABLE CPD PAPER}

A variety of educational approaches exist within UK dental schools, and institutions are constantly striving to improve the quality of their graduates. This study aimed to evaluate the self-reported confidence in, and clinical exposure to, paediatric dentistry at three UK dental schools (Liverpool, Manchester and Sheffield) over a three year period. Seventy-five percent of final year BDS undergraduates at the three dental schools completed an anonymous questionnaire capturing student self-reported clinical experience in seven core paediatric dentistry treatment skills, both in hospital and outreach settings. Visual analogue scales were used to record self-assessed confidence levels in aspects of paediatric dentistry and students were also asked to provide a written reflection of both their hospital and outreach placements. The results revealed that despite the variety of educational approaches taken, undergraduates reported very similar levels of clinical experience and confidence. Significant interschool differences in student experience were found with respect to the management of carious primary molars, believed to be a result of individual schools favouring different treatment regimes. Although outreach placements were seen as essential for gaining adequate student experience, the need to improve the consistency of teaching between hospital and outreach centres was highlighted. The study also emphasises the need to take care when using clinical targets in undergraduate teaching and identifies the potential benefits of undergraduate training in inhalation sedation. Finally, despite changes to the paediatric programmes with respect to dental trauma management, students remained lacking in confidence suggesting the need for further development.

\section{INTRODUCTION}

Dental educators and training providers are responsible for ensuring that new graduates demonstrate the clinical and professional outcomes that enable them to embark on a career as a general dental practitioner, as outlined by the General Dental Council (GDC). ${ }^{1,2}$ With up to $80 \%$ of dental graduates

\footnotetext{
${ }^{1}$ Clinical Teacher in Paediatric Dentistry, ${ }^{2}$ Academic Clinical Fellow/Honorary Speciality Registrar in Paediatric Dentistry, ${ }^{3}$ Senior Lecturer/Honorary Consultant in Paediatric Dentistry, School of Dentistry, University of Liverpool, Pembroke Place, Liverpool, L3 5PS; ${ }^{4}$ Professor of Dental Education/Honorary Consultant in Paediatric Dentistry, School of Dentistry, University of Manchester, Higher Cambridge Street, Manchester, M15 6FH; ${ }^{5}$ Research Fellow in Paediatric Dentistry, ${ }^{6}$ Professor/ Honourary Consultant in Paediatric Dentistry, Unit of Oral Health and Development, School of Clinical Dentistry, University of Sheffield, Claremont Crescent, Sheffield, S10 2TA

${ }^{*}$ Correspondence to: Mrs Siân Walley

Email: sianyw3@liv.ac.uk; Tel: +44 1517065207
}

\section{Refereed Paper}

Accepted 12 December 2013

DOI: $110.1038 /$ sj.bdj.2014.144

${ }^{\circ}$ British Dental Journal 2014; 216: 251-256 expected to work within the primary care sector providing dental care for the majority of children ${ }^{3,4}$ it is perhaps not surprising that a recent study supported by the Committee of Postgraduates Dental Deans and Directors (COPDEND) revealed that dental foundation (DF1) trainers had high expectations of trainee performance in paediatric dentistry skills. ${ }^{5}$ However, the 2003 Child Dental Health Survey showed that despite $43 \%$ of British five-year-olds experiencing dental caries, only $12 \%$ had evidence of restorative care, highlighting the ongoing decline in care indices across the UK. ${ }^{6}$ Several explanations have been proffered for this low care index, but it certainly prompts the question, how well does dental undergraduate education prepare graduates for the treatment of children?

The teaching of paediatric dentistry requires coherence and integration with the biomedical, oral biological and behavioural sciences in a multi-disciplinary curriculum. ${ }^{7}$ However, science and knowledge in dentistry are not a substitute for hands-on training. It has been said that "professional practices are refined by science and corrected by wisdom:. One of the challenges for dental schools is to provide students with adequate patient experience and clinical skill mix. ${ }^{9}$ The GDC states that 'students must have the opportunity to practice on a sufficient number and wide range of patients of all ages including those with special care requirements, with a wide range of treatment needs'. ${ }^{\text {Several studies }}$ have revealed a reduction in the paediatric clinical experience of dental students, particularly with respect to restorative procedures. ${ }^{10-15}$ This has been related to difficulties in recruiting adequate numbers of patients for an increasing student cohort and the reduction in childhood dental caries. ${ }^{16}$ Furthermore, patients who attend dental hospitals for treatment are not representative of those seen in general dental practice. ${ }^{17} \mathrm{~A}$ lack of appropriate undergraduate experience can have a negative effect on the ability and confidence of newly qualified dentists and hence can result in an increased number of 
Table 1 Percentage of students with self-reported clinical experience in core paediatric dentistry skills within hospital and outreach settings, over three years

Procedure/clinical setting

Year
Number of students

\begin{tabular}{|l|l|l|l|l|l|l|l|l|}
\hline \multicolumn{2}{|l|}{ Liverpool } & \multicolumn{4}{l|}{ Manchester } & \multicolumn{2}{l|}{ Sheffield } \\
\hline 2009 & 2010 & 2011 & 2009 & 2010 & 2011 & 2009 & 2010 & 2011 \\
\hline $\mathrm{N}=40$ & $\mathrm{~N}=72$ & $\mathrm{~N}=56$ & $\mathrm{~N}=49$ & $\mathrm{~N}=67$ & $\mathrm{~N}=75$ & $\mathrm{~N}=58$ & $\mathrm{~N}=50$ & $\mathrm{~N}=58$ \\
\hline
\end{tabular}

Fissure sealant

\begin{tabular}{|c|c|c|c|c|c|c|c|c|c|}
\hline Hospital & $88 \%$ & $92 \%$ & $100 \%$ & $53 \%$ & $39 \%$ & $31 \%$ & $100 \%$ & $100 \%$ & $100 \%$ \\
\hline Outreach & $100 \%$ & $97 \%$ & $98 \%$ & ${ }^{\mathrm{P}} 100 \%$ & P99\% & P99\% & $100 \%$ & $100 \%$ & $98 \%$ \\
\hline Either setting & $100 \%$ & $100 \%$ & $100 \%$ & $100 \%$ & $99 \%$ & $100 \%$ & $100 \%$ & $100 \%$ & $100 \%$ \\
\hline \multicolumn{10}{|l|}{ Restoration } \\
\hline Hospital & $98 \%$ & $94 \%$ & $93 \%$ & $44 \%$ & $46 \%$ & $40 \%$ & $98 \%$ & $98 \%$ & $93 \%$ \\
\hline Outreach & $98 \%$ & $97 \%$ & $96 \%$ & ${ }^{\mathrm{P}} 100 \%$ & ${ }^{\mathrm{P}} 100 \%$ & ${ }^{P} 100 \%$ & $100 \%$ & $98 \%$ & $98 \%$ \\
\hline Either setting & $100 \%$ & $100 \%$ & $100 \%$ & $100 \%$ & $100 \%$ & $100 \%$ & $100 \%$ & $100 \%$ & $100 \%$ \\
\hline \multicolumn{10}{|c|}{ Inicsal tip restoration* } \\
\hline Hospital & $70 \%$ & $58 \%$ & $75 \%$ & $36 \%$ & $24 \%$ & $18 \%$ & $76 \%$ & $73 \%$ & $63 \%$ \\
\hline Outreach & $66 \%$ & $67 \%$ & $70 \%$ & ${ }^{\mathrm{P}} 75 \%$ & ${ }^{P} 84 \%$ & P87\% & P91\% & P82\% & P $81 \%$ \\
\hline Either setting & $83 \%$ & $83 \%$ & $88 \%$ & $79 \%$ & $85 \%$ & $87 \%$ & $97 \%$ & $98 \%$ & $86 \%$ \\
\hline \multicolumn{10}{|c|}{ Preformed metal crown* } \\
\hline Hospital & $3 \%$ & ${ }^{\mathrm{H}} 20 \%$ & ${ }^{\mathrm{H}} 39 \%$ & $4 \%$ & $8 \%$ & $3 \%$ & ${ }^{H} 50 \%$ & H90\% & H88\% \\
\hline Outreach & $5 \%$ & $11 \%$ & $16 \%$ & ${ }^{\mathrm{P}} 44 \%$ & $P_{31 \%}$ & ${ }^{P} 36 \%$ & $20 \%$ & $41 \%$ & $45 \%$ \\
\hline Either setting & $8 \%$ & $23 \%$ & $48 \%$ & $45 \%$ & $33 \%$ & $37 \%$ & $63 \%$ & $92 \%$ & $90 \%$ \\
\hline \multicolumn{10}{|c|}{ Pulp therapy primary molar* } \\
\hline Hospital & $25 \%$ & $11 \%$ & $21 \%$ & $23 \%$ & $20 \%$ & $11 \%$ & $14 \%$ & $16 \%$ & $16 \%$ \\
\hline Outreach & $18 \%$ & $18 \%$ & $14 \%$ & ${ }^{P} 82 \%$ & P88\% & ${ }^{P} 86 \%$ & ${ }^{\mathrm{P}} 61 \%$ & ${ }^{\mathrm{P}} 60 \%$ & $P_{33 \%}$ \\
\hline Either setting & $38 \%$ & $20 \%$ & $32 \%$ & $86 \%$ & $94 \%$ & $85 \%$ & $64 \%$ & $60 \%$ & $40 \%$ \\
\hline \multicolumn{10}{|c|}{ Trauma treatment ${ }^{*}$} \\
\hline Hospital & ${ }^{H} 53 \%$ & ${ }^{\mathrm{H}} 49 \%$ & ${ }^{\mathrm{H}} 70 \%$ & $26 \%$ & $52 \%$ & $18 \%$ & $58 \%$ & $55 \%$ & $45 \%$ \\
\hline Outreach & $33 \%$ & $38 \%$ & $50 \%$ & ${ }^{\mathrm{P}} 46 \%$ & ${ }^{\mathrm{P}} 46 \%$ & $P_{37 \%}$ & $47 \%$ & $55 \%$ & $50 \%$ \\
\hline Either setting & $63 \%$ & $64 \%$ & $80 \%$ & $50 \%$ & $58 \%$ & $47 \%$ & $74 \%$ & $76 \%$ & $64 \%$ \\
\hline \multicolumn{10}{|c|}{ Extraction under local anaesthesia } \\
\hline Hospital & H90\% & H94\% & H98\% & $40 \%$ & $35 \%$ & $36 \%$ & $67 \%$ & $69 \%$ & $57 \%$ \\
\hline Outreach & $56 \%$ & $77 \%$ & $71 \%$ & P98\% & P88\% & P97\% & P91\% & P94\% & P98\% \\
\hline Either setting & $90 \%$ & $94 \%$ & $100 \%$ & $98 \%$ & $92 \%$ & $99 \%$ & $95 \%$ & $100 \%$ & $98 \%$ \\
\hline
\end{tabular}

inappropriate referrals to already pressurised specialist services. ${ }^{18}$

A variety of educational approaches exist within UK dental schools. The GDC, although prescriptive in expectations for a graduating dentist, does promote local innovation, development and flexibility within Bachelor of Dental Surgery (BDS) programmes. ${ }^{1}$ A study carried out in $2009^{9}$ investigated the views of final year undergraduates from three dental schools (Liverpool, Manchester and Sheffield) with regard to their perceived confidence and clinical experience in paediatric dentistry. The BDS programmes within these dental schools naturally vary, including how and when clinical paediatric dentistry is taught. Liverpool primarily has a hospital-based clinical paediatric dentistry programme with a ten-week outreach placement; clinical exposure in Manchester is provided mainly within outreach placements; while Sheffield has a combination of both hospital and outreach clinical teaching. In addition to this, Liverpool and Manchester provide students with the opportunity to treat children under inhalation sedation, while students only observe this treatment modality in Sheffield.

Although the 2009 data revealed that all institutions demonstrated compliance with GDC guidance, some inter-school disparity between graduates' experience and confidence was identified and areas of universal weakness highlighted. Following on from this, all three dental schools made 
changes to their paediatric programme. In relation to dental trauma, a shared portfolio of clinical scenarios was compiled for use in all three institutions in order to support case-based tutorials. In addition to this, within the University of Liverpool, new dental trauma symposiums were integrated into the curriculum and students were given more opportunities to attend emergency and consultant-led trauma clinics. Findings were also disseminated to clinical tutors within both hospital and outreach-based clinics to highlight where efforts needed to be made to enhance paediatric clinical learning for students.

The present study thus aimed to evaluate the self-reported confidence in, and clinical exposure to, paediatric dentistry at the three UK dental schools (Liverpool, Manchester and Sheffield) over a three year period.

\section{METHOD AND MATERIALS}

Over three consecutive years (2009-2011), all final year BDS undergraduates at Liverpool (2009, $\mathrm{n}=70 ; 2010, \mathrm{n}=86 ; 2011, \mathrm{n}=76$ ), Manchester (2009, $\mathrm{n}=85 ; 2010, \mathrm{n}=79$; 2011, $\mathrm{n}=72$ ) and Sheffield (2009, $\mathrm{n}=63$; 2010, $\mathrm{n}=50 ; 2011, \mathrm{n}=84$ ) dental schools were asked to complete an anonymous twosided questionnaire a few weeks before their final examinations.

The questionnaires investigated student self-reported clinical experience in seven core paediatric dentistry treatment skills. These included: fissure sealants; intra-coronal restorations; preformed metal crowns (PMC); primary molar pulp therapy; dental trauma and extractions. Students recorded exposure to treatments with a yes/no response for experience gained in hospital, outreach or both settings.

Self-assessed confidence levels in aspects of paediatric dentistry including examination, diagnosis and treatment planning, restorative procedures, referral of children for a general anaesthetic, explanation of risks and instructions, preventative treatments, management of dental trauma and provision of routine care within general dental practice were recorded using a visual analogue scale (VAS). Students were asked to place a vertical mark on a $10 \mathrm{~cm}$ line, where $0.0 \mathrm{~cm}$ represented 'no confidence' and $10 \mathrm{~cm}$ represented 'complete confidence. Scores were then measured by the authors using a $10 \mathrm{~cm}$ ruler, to provide a numerical value.

In addition to this, to gain a more meaningful insight of students' perspectives of their paediatric dentistry clinical experiences, students were also asked to provide a written reflection of both their hospital and primary care outreach placements.

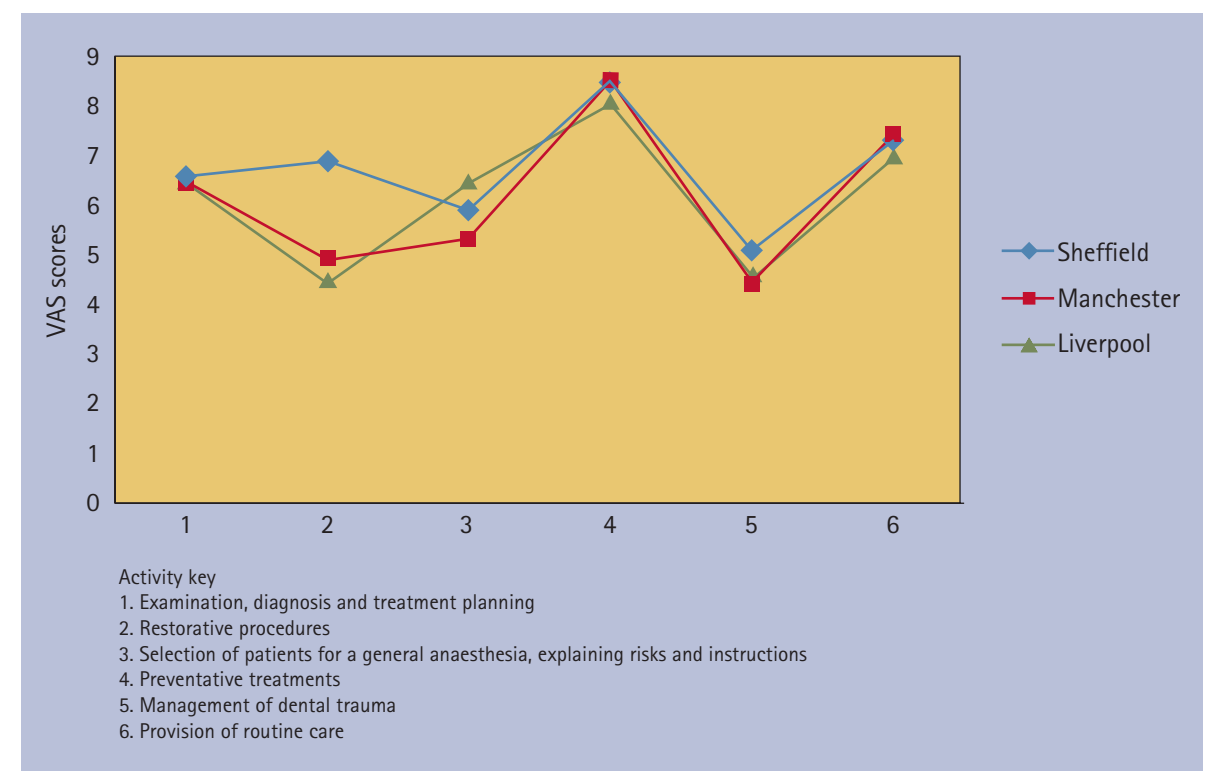

Fig. 1 The perceived confidence levels for generic paediatric dentistry skills in three UK dental schools

\section{DATA ANALYSIS}

Data were entered into SPSS v19 (IBM Corporation, New York, United States of America) for simple descriptive analysis. Inter-school differences in core clinical skills were explored using a chi-squared test, whereas inter-setting differences between hospital and outreach were analysed using a McNemarer test. Preliminary data for confidence levels showed VAS data were normally distributed, thus a one-way analysis of variance (ANOVA) followed by a Tukey test were used to determine statistically significant differences in means. Significance levels for all investigations were set at $\mathrm{p}<0.05$.

Qualitative data were analysed using an inductive process of thematic content analysis, based on grounded theory of data analysis. ${ }^{19}$ In accordance with the process, recurrent themes in student responses were identified by the authors, the most prevalent of these themes being presented in the results section under each thematic heading.

\section{RESULTS}

A total of 525 out of a possible $700(75 \%$ response rate) final year dental students participated in the survey across the three dental schools; Liverpool, $\mathrm{n}=168$ (74\% response), Manchester, $n=191$ (81\% response) and Sheffield, $n=166(70 \%$ response). Preliminary analysis revealed no statistical difference in responses according to gender, thus data from male (45\%) and female (55\%) respondents were pooled for subsequent analysis.

\section{Clinical experience}

Across schools there were similarly high levels of experience evident for the provision of fissure sealants (range, 99-100\%), restorations (100\%) and extractions under local anaesthesia (range, 90-100\%). Table 1 demonstrates the percentage of students from each school who had self-reported experience in the seven key clinical skills. Data are given separately for experiences relating to hospital and outreach settings and for each of the three years of graduation (2009-2011).

Lower levels of experience and significant inter-school differences ( $p<0.05$, Chisquared test) were noted for the provision of incisal tip restorations (range, 79-98\%), preformed metal crowns (range, 8-92\%), pulp therapy of primary molars (range, 20-94\%) and management of dental trauma (range, 47-80\%).

There was a marked difference in clinical skill experience gained during hospital and outreach placements (Table 1). Significantly higher levels of experience were gained in outreach for Manchester students for all procedures ( $p<0.05$, McNemarer test). Sheffield students attained significantly higher levels of outreach experience for incisal tip restorations, primary pulp therapies and extractions under local anaesthesia, however, were more likely to place a PMC within a hospital setting. For Liverpool students, statistically higher levels of clinical experience were gained in a hospital setting for PMCs, management of dental trauma and extractions under local anaesthesia ( $p<0.05$, McNemarer test).

Over the three consecutive study years there was an increase in the number of PMCs placed in Liverpool (2009: 8\% to 2011: 48\%) and Sheffield (2009: 63\% to 2011: 90\%), also students at Liverpool gained an increased level of clinical exposure to the management of dental trauma (2009: 63\% to 2011: 80\%). 


\section{Table 2 Mean visual analogue scale (VAS) for self-reported confidence of students in core areas of paediatric dentistry-related procedures}

\begin{tabular}{|c|c|c|c|}
\hline Activity & Liverpool & Manchester & Sheffield \\
\hline & overall $(n=168)$ & overall $(n=191)$ & overall $(n=166)$ \\
\hline Examination, diagnosis and treatment planning & $6.5(1.30)$ & $6.4(1.30)$ & $6.6(1.07)$ \\
\hline Restorative procedures & $4.5(2.46)$ & $4.9(2.51)$ & L.M $6.9(1.70)$ \\
\hline Selection of patients for $\mathrm{GA}$, risks and instructions & S,M $6.5(1.60)$ & $5.3(1.80)$ & M5.9 (1.78) \\
\hline Preventative treatments & $8.1(1.31)$ & เ8.5 (1.11) & เ8.5 (1.23) \\
\hline Management of dental trauma & $4.6(2.02)$ & $4.5(2.09)$ & M5.1 (1.93) \\
\hline Provision of routine care & $7.0(1.60)$ & $7.4(5.00)$ & $7.3(1.27)$ \\
\hline
\end{tabular}

\section{Perceived confidence}

Preliminary analysis revealed no significant inter-year differences for VAS scores. Therefore, year groups were pooled for subsequent analysis. Students revealed that they felt most confident in providing preventative treatments (Liverpool VAS $=8.1$; Manchester VAS $=8.5$; Sheffield VAS $=8.5$ ). Students felt least confident in managing dental trauma (Liverpool VAS $=4.6$; Manchester VAS $=5.1$; Sheffield VAS $=4.5$.

Figure 1 and Table 2 provide the mean overall VAS scores for schools. Inter-school differences were observed for restorative procedures, the selection of patients for a general anaesthetic, preventative treatments and management of dental trauma $(\mathrm{p}<0.05$, ANOVA).

\section{Student perceptions of hospital and outreach placements}

Ninety-two percent of respondents provided a written statement of their hospital and/ or outreach experience. From analysis of the qualitative data, three major categories emerged from the written transcripts. These broadly related to the type and amount of clinical exposure, knowledge gained and preparedness for later general dental practice.

\section{Clinical exposure}

Students' described differences in the amount of clinical exposure they had received in both settings and reflected on differences in the patient case and skill mix. Within a hospital setting, students commented on high levels of failed patient attendances and limited practical experience. This contrasted to the greater numbers of child patients seen and clinical experience gained within outreach primary care settings.

'Not enough patients, many fail to attend' (Re hospital clinic)

'The tutorials were very good but the clinical experience was not sufficient without outreach I would have had little experience'
(Sheffield student, re hospital clinic)

'Nothing practical therefore not very valuable' (Re hospital clinic)

'Almost all of my experience of the treatment of children was through outreach. This was an invaluable experience for me'. (Re outreach clinic)

'Really enjoyed outreach teaching and working with a dental nurse. This is where I've learnt most about paediatric dentistry' (Re outreach clinic)

Although students reported that a higher numbers of patients were treated within an outreach setting, they acknowledged that the range of clinical procedures undertaken was less complex and diverse than one would expect to see and treat in a hospital environment.

'Main treatment carried out involved fissure sealants' (Re outreach clinic)

'Treatment mix was poor, only got to do preventative treatments' (Re outreach clinic)

'Hospital is good for exposure to rarer conditions' (Re hospital clinic)

'I was very lucky to be allocated a patient who required a varied treatment plan.' (Re hospital clinic)

Students also commented on an apparent disparity in the number and diversity of clinical skills completed by each student during both outreach and hospital clinics.

'I was lucky to always have paediatric patients in the hospital but others in my year where not:' (Re hospital clinic)

'Very helpful depending on which outreach centre you go to, experience can be very varied.' (Re outreach clinic)

'Once students have reached clinical targets patients should be passed to another student so that there is a fairer distribution of the amount of clinical experience obtained' (Re hospital clinic)

'Range of experience depends on outreach placement.' (Re outreach clinic)

\section{Education and knowledge}

Students reflected on the quality of teaching and learning within the two settings, which both had examples of excellent support. Students valued enthusiastic and knowledgeable teaching staff.

'Quality of teaching is excellent!' (Re hospital clinic)

'Teaching clinics are good. Staff always friendly and tutors very supportive' (Re hospital clinic)

'Staff and teaching excellent in my experience' (Re hospital clinic)

'Loved every minute. Excellent teaching and resources available' (Re hospital clinic)

Students also commented on the usefulness of the case-based scenarios implemented in 2010 and the positive effect they had on their learning experience in dental trauma.

'Scenarios on clinics are very good'

'I like the trauma cases, although would like a booklet of these'

'Case studies helpful'

However, some felt that the learning and teaching experience in outreach placements could be improved and some alluded to differences in opinions regarding treatment options and decision-making between outreach and hospital placements.

'Teaching was limited. Few sessions to discuss teaching' (Re outreach clinic)

'Some of the supervisors seemed less confident about what we should be doing' (Re outreach clinic)

'Treatment plans are often different to hospital. Advised to avoid LA [local anaesthesia] if possible' (Re outreach clinic)

'The primary care practices did less and did no stainless steel crown work' (Re outreach clinic)

\section{Preparedness for later dental practice}

The third theme to emerge was an appreciation of how well each setting prepared students for real life practice. Students reported that outreach primary care settings increased their overall clinical confidence in treating paediatric dentistry 
patients and stated it helped them to feel ready for later dental practice.

'Outreach provided me with the clinical experience needed to increase my confidence in treating children' (Re outreach clinic)

'Have enjoyed my time in outreach and have learnt a great deal. I would feel comfortable seeing a child in general practice now' (Re outreach clinic)

'Very good, increased confidence and experience in treating children' (Re outreach clinic)

'Good, real life situations' (Re outreach clinic)

\section{DISCUSSION}

A fundamental finding from this study was that, despite the variety of approaches in programme design, undergraduates from all three schools reported very similar levels of clinical experience and confidence, with each institution satisfying the expectations of the GDC. ${ }^{1,2}$ The majority of students gained clinical experience in the placement of fissure sealants, restorations and extractions. This is consistent with findings from the COPDEND study, which reported no disparity between DF1 trainers' expectations and the clinical experience of new graduates. ${ }^{5}$ The overall response rate was 75\%, which is considered acceptable for a questionnaire-based survey among student populations. However, it is acknowledged that some sampling bias may limit the generalisability of the findings. It would therefore be interesting to determine whether there were, in fact, any differences in the clinical achievements and confidence levels of non-responders and responders.

With respect to the management of carious primary molars, differences in clinical experience found for the three student groups may be explained by different treatment regimens being favoured by individual schools. In particular, the consistently high student experience in the placement of PMCs at Sheffield, and the increasing experience at Liverpool, relates to timing of the integration of the non-invasive Hall technique ${ }^{20}$ into the undergraduate curriculum. On the other hand, Manchester students had a significantly higher exposure to primary molar pulp therapies, with less reliance on the Hall technique. While it is essential that all students should receive practical instruction in how to undertake a primary molar pulpotomy using evidencebased materials, it is not feasible to ensure that every student has the opportunity to carry this out for a real patient. Furthermore, within the international paediatric dentistry community there has been a shift away from the conventional pulpotomy towards more modern caries management and adoption of indirect pulp therapies. Indeed it may be argued that the undergraduate paediatric dentistry curriculum should place greatest importance on ensuring graduates are able to diagnose caries accurately and thus instigate more preventive and biologicallybased therapies.

Management of dental trauma has previously been reported as an area where general dental practitioners feel least prepared to treat children. ${ }^{21}$ Unfortunately, undergraduates at all three institutions were found to be least confident in this area, despite the implementation of curriculum changes. Surprisingly, even with an increase in clinical exposure at Liverpool dental school, student confidence levels did not improve. The presentation of children with acute dental trauma is a common but unpredictable occurrence in both primary and secondary care settings. Thus it would be impossible to ensure that all students had an equable exposure to this patient group. Educators need to be more creative in their effort to provide more practical instruction in this key area of need. Qualitative data did reveal that students found the traumabased scenarios helpful to learning and perhaps further development of these would be beneficial. The use of virtual simulated patients has proved very successful in teaching clinical reasoning skills to undergraduate medics and would warrant consideration for teaching of paediatric dental trauma. ${ }^{22}$

Another interesting finding arising from the qualitative data was the suggestion that students benefited from providing treatment for children under inhalation sedation. A previous study of undergraduate experience in UK dental schools (1997-2001) stressed the importance of increasing the provision of inhalation sedation within the dental curriculum. ${ }^{10}$ Despite this, not all BDS institutions currently provide the facilities for undergraduates to undertake treatments with inhalation sedation. The subject of inhalation sedation within the dental curriculum was not the focus of this report, however, the results indicate this area may merit future investigation.

Outreach placements were seen as essential for students to gain satisfactory clinical experience, and this was evidenced by both the quantitative and qualitative data. This finding is supported by previous studies ${ }^{18}$ that also reported that students perceived time spent within outreach primary care centres as enhancing their confidence levels in treating children ${ }^{23,24}$ and leaving them feeling better prepared for dental practice. ${ }^{25}$ Interestingly, this study revealed that Manchester students, who had the longest periods of time within an outreach setting, did not necessarily have the highest levels of confidence. The qualitative data suggested that some students were confused by disparity in clinical opinions between different trainers, which is consistent with previous research. ${ }^{23,26}$ Similarly, the COPDEND report expressed concerns over new graduates being guided by DF1 trainers with differing clinical opinions to their hospital-based tutors. ${ }^{5}$ It is therefore important that outreach placements are selected carefully and that emphasis is placed on the continuity of teaching between dental school and outreach providers. This study would also support the need for students to gain confidence and knowledge in paediatric procedures while at dental school before attending outreach, particularly in those procedures that have newer evidence-based guidance, such as the Hall technique for placement of PMCs. ${ }^{20}$ Any marked disparity in opinion or advice given could lead to anxiety and confusion in inexperienced undergraduates.

A final point of interest, arising from the qualitative enquiry, was that of clinical targets. These are increasingly used within dental schools as a means of monitoring student progress. While these have some educational merit, it is important that students do not become 'target-focused'. Students should value seeing all children for the unique opportunity they present to improve communication and behavioural skills, monitor the developing dentition and undertake holistic short and long-term treatment planning.

\section{CONCLUSION}

In conclusion, this study has shown that there are some inconsistencies in teaching of paediatric dentistry between hospital and outreach centres. Some differences also exist between the three dental schools in terms of student exposure to pulpotomy and preformed metal crown techniques. Student confidence in managing dento-alveolar trauma is universally low and this remains an area where efforts should be made to improve undergraduate learning.

Thanks are given to Dr Girvan Burnside, statistician at University of Liverpool for his help with the statistical analysis. Professor Callum Youngson (Head of Liverpool Dental School) and Professor Paul Speight (Dean of Sheffield Dental School) are also acknowledged for supporting this study and our endeavours to improve the teaching of paediatric dentistry. Finally, we are grateful for the time and honest reflections given by our undergraduate dental students.

1. General Dental Council. Preparing for dental practice, dental team learning outcomes for registration. London: GDC, 2003.

2. General Dental Council. The first five years: a framework for undergraduate dental education. 
3rd ed. London: GDC, 2008.

3. Tickle $M$, Threlfall A G, Pilkington $L$, Milsom K M, Duggal M S, Blinkhorn A S. Approaches taken to the treatment of young children with carious primary teeth: a national cross-sectional survey of general dental practicioners and paediatric specialists in England. Br Dent J 2007: 203: E4.

4. Dailey Y M, Milsom K, Pilkington L, Blinkhorn A S, Threlfall $A$, Tickle M. A qualitative investigation of the influence of time since graduation on English dentists' approach to the care of young children. Int J Paed Dent 2007; 17: 336-344.

5. Gilmour A, Jones R, Bullock A D. Dental foundation trainers' expectations of a dental graduate: final report Wales Deanery/Cardiff University, March 2012.

6. Office for National Statistics. Children's dental health in the United Kingdom, 2003: summary report London: ONS, 2005.

7. Licari FW, Chambers D W. Some paradoxes in competency-based dental education. J Dent Educ 2008; 72: 8-18.

8. Cogan M L. Towards a definition of profession. Harvard Educational Review 1953; 23: 33-50.

9. Rodd H D, Farman M, Albadri S, Mackie I C. Undergraduate experience and self-assessed confidence in paediatric dentistry: comparison of three UK dental schools. Br Dent J 2010; 208: 221-225.

10. Seddon R P. Undergraduate experience of clinical procedures in paediatric dentistry in a UK dental school during 1997-2001. Eur J Dent 2004; 8:
172-176.

11. Ripa L W. Change in care patterns in a dental school children's dentistry clinic. J Dent Educ 1986; 50: 309-311.

12. Walker J, Pinkham J, Jakobsen J. Paediatric patient yield in 1978 and 1983. J Dent Educ 1986; 50: 614-615.

13. Bell R A, Barenie J T, Myers D R. Trends and implications of treatment in predoctoral clinical paedodontics. J Dent Educ 1986: 50: 722-725.

14. Bimstein E, Eidelman E. Treatment trends during a thirteen-year period in a student paediatric dentistry clinic. J Dent Child 1997; 64: 267-271.

15. Finucane D, Nunn J H, O'Connell A C. Paediatric dentistry experience of the first cohort of students to graduate from Dublin Dental School and Hospital under the new curriculum. Int J Paediatr Dent 2004; 14: 402-408.

16. Pitts N B, Boyles J, Nugent Z J, Thomas N, Pine C M. The dental caries experience of 5 -year-old children in Great Britain (2005/6). Surveys coordinated by the British Association for the Study of Community Dentistry. Community Dent Health 2007; 24: 59-63.

17. Holloway P J, Dixon P A. Extra-mural experience of undergraduate dental students. Br Dent J 1977; 143: 146-150.

18. Hunter $M$, Chaudhry U. Paediatric dentistry in outreach settings: an essential part of undergraduate curricula?. Eur J Dent Educ 2009; 13: 199-202.

19. Burnard P, Gill P, Stewart $K_{1}$ Treasure $E_{1}$ Chadwick B.
Analysing and presenting qualitative data. Br Dent $J$ 2008; 204: 429-432.

20. Innes N P, Stirrups D R, Evans D J, Hall N, Leggate M. A novel technique using preformed crowns for managing carious primary molars in general practice - a retrospective analysis. Br Dent J 2006 200: 451-454

21. Jackson N G, Waterhouse P J, Maguire A. Management of dental trauma in primary care: a postal survey of general dental practitioners. $\mathrm{Br}$ Dent J 2005; 198: 293-297.

22. Cook D A, Triola M M. Virtual patients: a critical literature review and proposed next steps. Med Educ 2009; 43: 303-311.

23. Smith $M$, Lennon M A, Brook A H, Robinson PG. A randomized controlled trial of outreach placement's effect on dental students' clinical confidence. J Dent Educ 2006; 70: 566-570.

24. Lynch C D, Ash P J, Chadwick B. Student perspectives and opinions on their experience at undergraduate outreach dental teaching centre at Cardiff: a 5-year study. Eur J Dent Educ 2010; 14: 12-16.

25. Modifi M, Strauss R, Pitner L L, Sandler E S. Dental students reflections on their community-based experiences: the use of critical incidents. J Dent Educ 2003; 67: 515-523.

26. Eriksen $H$, Bergdahl M, Byrkjeflot $L$, Crossner $C$, Widström $E_{\text {, Tillberg A. Evaluation of a dental }}$ outreach teaching programme. Eur J Dent Educ 2011; 15: 3-7. 